\title{
Os Ambientes Virtuais como espaço para o desenvolvimento da autonomia sociocultural: uma (inter)relação possível?
}

Virtual environments as spaces for learner sociocultural autonomy development: a feasible connection?

Anderson Silva MATOS (UFRJ) ${ }^{1}$ Christine NICOLAIDES (UFRJ) ${ }^{2}$

\section{RESUMO}

À luz de pressupostos acerca do desenvolvimento da autonomia na aprendizagem de línguas, que contemplem a teoria Sociocultural (VYGOTSKY, 1984) e observe ambientes virtuais como espaços semióticos sociais (GEE, 2004; GEE, 2005), o presente artigo analisou as relações possíveis entre a promoção da Autonomia Sociocultural do aprendiz e o uso de ambientes virtuais através da agência observada pelos membros desses ambientes. Este artigo propõe o uso de ambientes virtuais como um campo promissor para a promoção da autonomia sociocultural do aprendiz. Observamos o uso de ambientes virtuais e a relação desses com a participação dos alunos com o intuito de analisar a agência dos interactantes como usuários de tais ambientes. Os resultados indicam que os ambientes virtuais observados possibilitam maior engajamento no aprendizado e consciência por parte dos aprendizes como membros atuantes de um grupo de apoio mútuo com um objetivo em comum: desenvolver sua proficiência na língua alvo.

Palavras-Chave: Autonomia, Teoria sociocultural, Agência, Tecnologias digitais

\section{ABSTRACT}

In light of a theory about language learner autonomy which comprehends Sociocultural theory (VYGOTSKY, 1984) and that observes virtual environments as social semiotic spaces (GEE, 2004; GEE, 2005), this article analyzes possible connections between the promotion of sociocultural learner autonomy and the use of virtual environments perceived through the agency of members of these environments. This article poses that using virtual environments is a promising space for sociocultural autonomy development. We also focused on the relation between the use of virtual environments and students' participation in order to contemplate their agency as users of such environments. Results indicate that the virtual environments allowed for a more prominent engagement from learners in the learning process and a development of awareness from learners as active members of a group of mutual support with a common goal: developing their proficiency in their desired language.

Keywords: Learner autonomy, Sociocultural theory, Agency, Digital technologies

\footnotetext{
${ }^{1}$ Universidade Federal do Rio de Janeiro. Rio de Janeiro, Rio de Janeiro, Brasil. Doutorando no Programa de Pós-Graduação Interdisciplinar em Linguística Aplicada; matos.andersonsilv@gmail.com

${ }^{2}$ Universidade Federal do Rio de Janeiro. Rio de Janeiro, Rio de Janeiro, Brasil. Programa de Pós-Graduação Interdisciplinar em Linguística Aplicada. ORCID: https://orcid.org/0000-0003-0167-3592; christine.nicolaides@gmail.com
} 


\section{Introdução}

Observando a popularização e utilização de tecnologias digitais em salas de aula, é possível pensar em uma maior integração entre os diferentes níveis de letramento ou de 'multiletramentos' (como proposto pelo New London Group, 2000) e a crescente utilização de tecnologias digitais nos ambientes de ensino, sejam esses ambientes presenciais ou virtuais ou, até mesmo, uma blendagem ${ }^{3}$ deles (KNOBEL; LANKSHEAR, 2010; LANKSHEAR; KNOBEL, 2008; MILLS, 2016). Neste artigo, buscamos, por meio de análise da implementação e integração de ambientes virtuais em aulas de um projeto/curso de línguas, compreender possíveis consequências de um uso consciente das ferramentas digitais com vistas à promoção do que entendemos por autonomia sociocultural (OXFORD, 2003) dos aprendizes promovendo, assim, maior empoderamento no processo de ensino-aprendizagem de línguas.

Este artigo se divide em três partes, sendo uma primeira abordando a possível interação entre as tecnologias digitais e o ensino de línguas. Em um segundo momento, discutimos o conceito de autonomia, integrando-o à perspectiva da Teoria Sociocultural (VYGOTSKY, 1984) e ao contexto de ensino e aprendizagem (em especial, mas não restrito, neste artigo, o ensino e aprendizagem de línguas). A partir dessas argumentações, em uma terceira seção, utilizamos exemplos de utilização de ambientes virtuais em aulas de um projeto de curso de línguas para apontar possíveis caminhos para um aprendizado que se beneficie das tecnologias digitais para um processo de ensino-aprendizagem cada vez mais autônomo e socioculturalmente responsável (MATOS, 2017). Em conclusão deste artigo, tecemos nossas considerações a respeito das questões aqui abordadas para sinalizar possíveis desdobramentos pedagógicos que promovam a autonomia sociocultural no ensino e aprendizagem de línguas por meio de ferramentas tecnológicas em ambientes virtuais.

\section{Tecnologias digitais, sociedade e ensino de línguas}

A constante integração de tecnologias digitais em nossa sociedade já provoca debate sobre os perigos de sua implementação. Como trazem à tona Bauman e Lyon, no livro Liquid Surveillance: $a$ conversation (BAUMAN; LYON, 2012), é preciso estar atento para o fato de que a vida hodierna traz duas importantes características que fazem toda a diferença em nosso cotidiano: a primeira seria a questão da mobilidade física que nos permite ir e vir com mais facilidade para diferentes cantos do mundo; a outra seria a mobilidade virtual, que nos possibilita, sem necessariamente nos movimentarmos

\footnotetext{
${ }^{3}$ Vocábulo originário da língua inglesa (blending), cujo significado é "mistura para homogenizar um produto ou uma substância (ex.: blendagem de minério, blendagem de resíduos)", aqui neste texto utilizado para quando o ensino é feito por meio de ambientes virtuais e presenciais em um mesmo curso. In: Dicionário Priberam da Língua Portuguesa [em linha], 20082013, https://dicionario.priberam.org/blendagem. Acesso em 27 nov. 2018.
} 
fisicamente, estar em contato com várias realidades por meio de mídias sociais, correios eletrônicos, navegação na internet, a própria interação em textos que lemos e nos possibilita opinar sobre os textos diretamente com o autor etc. Se por um lado essas novas facetas do mundo pós-moderno parecem positivas por abrir nosso leque de escolhas, sejam elas sociais, profissionais, econômicas, culturais, por outro, Bauman e Lyon afirmam que essa movimentação deixa rastros e não mais podemos agir de forma anônima e efêmera.

O fenômeno das tecnologias digitais, dos dispositivos móveis e das redes sociais é parte da sociedade e, mesmo que seja importante observar que as tecnologias digitais não são neutras e geram divisores sociais (ver BUZATO, 2006), não é mais cabível restringir seu uso, especialmente em sala de aula. Por outro lado, um dos aspectos perversos, no que diz respeito à inserção de tecnologias, é o fator para qual Mills (2010, p. 3) nos chama atenção:

[...] alunos da escola primária gostam de utilizar tecnologia para a produção de mídia digital, mas não podemos assumir que todos os alunos têm as habilidades necessárias para a participação no conhecimento da economia simplesmente por eles gostam de jogar videogames por prazer. (MILLS, 2010, p.3)

O que autora pretende alertar é que a própria indústria tecnológica está ligada ao mundo corporativo que, em grande parte, serve aos seus próprios interesses econômicos. Assim, para aqueles que não conseguem utilizar a tecnologia para obter um maior acesso à informação a seu favor, acabam por ficar marginalizados do ponto de vista social, econômico e cultural. Em outras palavras, a tecnologia pode apenas deixar seus usuários dependentes dela, ao invés de que ela sirva para auxiliá-los a ascenderem na escala social. Esse fenômeno por si só, segundo Mills, nos faz repensar sobre a promoção do letramento digital.

Portanto, ao invés da proibição do uso de tecnologia, cuja prática no ensino da rede escolar básica infelizmente parece ser frequente, é mister refletir-se junto aos aprendizes, afinal, é a serviço de quem ou de que interesses essas tecnologias estão cada vez mais inseridas em nosso cotidiano. Faz-se necessário ainda discutir, sobretudo, o uso dessas tecnologias como forma de suporte a práticas pedagógicas e de integração não só entre alunos e professores em ambientes virtuais, mas de integrar também, através da reflexão crítica, a realidade social do aprendiz, almejando seu empoderamento e emancipação em favor de melhores condições de vida para sua comunidade de prática (LAVE; WENGER, 1991).

Ainda é importante acrescentar que, ao se trabalhar com tecnologias digitais no ensino, não há somente uma forma, mas uma gama de configurações (entre elas o ensino à distância, o ensino misto e o ensino presencial com componentes extras - opcionais - virtuais ${ }^{4}$ ) que lidam com diversos novos tipos de papéis para o professor (orientador, tutor, monitor, explorador, problematizador, apenas para citar

\footnotetext{
${ }^{4}$ ARAÚJO, 2014; PERKEL, 2010. 
alguns). Neste artigo, focamos no ensino presencial com componentes virtuais que auxiliem o professor em seu fazer didático em sala de aula e fora dela 5 .

É necessário aqui reforçar a importância da participação de direções e responsáveis por políticas de ensino no incentivo aos professores para a constante atualização, encorajando-os para participar de cursos, palestras e outras atividades de aprimoramento sobre o uso de ferramentas tecnológicas. O professor deve estar ciente e engajado em práticas que promovam não somente a autonomia de seus aprendizes, mas o de seu próprio aprimoramento profissional. Entretanto, se essas práticas forem cerceadas com restrições de carga horária para seu desenvolvimento (como, por exemplo, a não liberação de professores para eventos por parte de secretarias ou a implementação de projetos pedagógicos e, portanto, sem a participação e reflexão por parte dos professores sobre o uso dessas ferramentas), o engajamento de profissionais tende a diminuir e suas possibilidades de ampliar e melhorar a qualidade do processo de ensino e aprendizagem serão cada vez mais restritas. Mesmo que professores não consigam ser totalmente ofuscados por falta de oportunidade, por parte das secretarias e coordenações que regem seu expediente e práticas profissionais, um profissional sob tais circunstâncias, pode ter o desenvolvimento de sua autonomia, e da promoção de um ensino que promova a autonomia, limitados.

\section{Autonomia e agência no contexto de ensino e aprendizagem de línguas - uma questão sociocultural}

Ao se falar de autonomia, o consenso a identifica como atitude individual. Até mesmo na literatura canônica sobre o assunto em contexto escolar, como a concepção formulada por Henri Holec (1981, p. 3) como a "capacidade de responsabilizar-se pelo próprio aprendizado", foca em um aspecto individual.

No entanto, um outro modelo proposto por Benson (2001) subdivide a autonomia do aprendiz em três perspectivas: a versão técnica que foca nos recursos com os quais o aluno lida para aprender determinado assunto, seja por artefatos físicos (com ferramentas) ou simbólicos (a linguagem, por exemplo); a versão psicológica que tem um enfoque na motivação do aluno para seu aprendizado autônomo (aqui questões como estilos de aprendizagem e crenças dos alunos são levadas em conta, por exemplo) e, por último, a versão política que lida com os motivos pelos quais o aluno se torna autônomo e como sua autonomia causa impacto em seu pensar e fazer crítico (nessa versão o autor sugere o controle por parte do alunos em relação aos conteúdos da aprendizagem, por exemplo).

Essas versões de autonomia expandem a concepção clássica por observar não somente o aspecto individual, mas também o ambiente de aprendizagem e as estratégias dele advindas (na versão técnica). Já os aspectos psicológicos enfatizam a importância de o aprendiz compreender como ele aprende segundo suas características, enquanto que na versão política ele ou ela é estimulado a ter mais voz no processo de ensino e aprendizagem por meio do pensamento crítico. No entanto, se levarmos em consideração a concepção de aprendizado mediado (presente na perspectiva sociocultural de autonomia proposta por

\footnotetext{
${ }^{5}$ Para uma discussão mais aprofundada sobre tipos de papéis do professor em contextos de EAD, ver TAVARES, 2007). 
OXFORD, 2003) em uma perspectiva Vygotskyana (1984), a concepção de autonomia ainda carece de maior aprofundamento quanto às origens e consequências, levando em consideração o meio sociocultural que leva o indivíduo a um aprendizado autônomo.

Assim, ao criticar o modelo proposto por Benson (2001), Oxford (2003) propõe a inserção de duas versões de autonomia e serem incorporadas ao modelo, as versões Sociocultural I e II. A primeira observa a relação entre pares menos e mais experientes (por exemplo professor e aluno, aluno e aluno), cujo objetivo é fazer com que o aprendiz (geralmente o par menos experiente) diminua a distância entre o que ele somente consegue fazer em grupo e o que já consegue levar a cabo sozinho. Já a autonomia sociocultural II diz respeito da relação entre o aprendiz e sua comunidade de prática (LAVE; WENGER, 1991). Dang (2010), ao relacionar os conceitos de autonomia em seu contexto de atuação, aponta que:

Uma perspectiva sociocultural enxerga a autonomia do aprendiz como uma variável socialmente construída (SMITH; USHIODA, 2009), constituída durante a negociação do aprendiz com sua comunidade. Em sendo membro de uma comunidade, qualquer indivíduo precisa lidar com assuntos diversos e com as relações sociais diariamente, e a autonomia é produzida ${ }^{6}$ na execução de tais processos. (DANG, 2010, p. 4)

Esses contextos de atuação nos levam então a considerar que, ao se observar as ações em meio a uma comunidade, estamos falando, na verdade, de agência. Hunter e Cook (2007) definem agência como "a capacidade de agir com iniciativa e efeito em um mundo socialmente construído" (2007, p. 75). Em seu artigo, os autores ainda discorrem sobre as proposições de teóricos para a compreensão do termo e a conexões possíveis com o estudo da autonomia. Nesta pesquisa, entendemos agência não apenas como a ação livre, mas o resultado consciente e crítico da gama de escolhas técnicas e psicológicas e opções presentes dadas as configurações do meio social, incluindo suas restrições e consequências. Agência, portanto, se liga ao estudo de autonomia por serem as atitudes de indivíduos que podem ou não indicar noções de autonomia inteligíveis ao olhar do pesquisador.

Retomando o foco para a relevância do contexto social do aprendiz para sua autonomia, é possível perceber a relevância do conceito de comunidades de prática ${ }^{7}$ (LAVE; WENGER, 1991; WENGER, 2002) na observação da interação dos membros desses grupos. No entanto, dada à natureza fluida e dos papéis complexos de ambientes virtuais, uma perspectiva focada em grupos talvez não seja a mais apropriada para enfatizar as propriedades de novo contexto. Uma possível alternativa é um olhar mais voltado para o ambiente virtual e para as possibilidades de interação por eles proporcionados. Uma perspectiva que observe as propriedades do ambiente beneficiaria a professores pois, mesmo sendo relevante pensar em seu grupo, pensar no ambiente onde ele interage, e como o ambiente no qual atua proporciona a interação, pode ser mais proveitoso na análise e seleção prévias de tipos de ambientes

\footnotetext{
${ }^{6}$ Em respeito à contribuição de DANG, foi mantido seu texto integral que integra a palavra "produzida". No entanto, acredito em autonomia como processo a ser desenvolvido, não como produto final.

7 Segundo Lave \& Wenger (1991) Comunidades de Prática (COPs) são compreendidas como grupos de pessoas que compartilham um interesse comum por meio do qual aprendem na medida que interagem regularmente com seus pares.
} 
virtuais (fóruns, wikis, ambientes virtuais de aprendizagem, redes sociais, apenas para citar alguns) e de como melhor utilizá-los em seu fazer pedagógico. Para isso, acreditamos que pensar na promoção da autonomia em contextos digitais pode ser associado à visão de Gee (2004) de espaços semióticos sociais ou, mais precisamente, de espaços de afinidade.

Para Gee (2004), os espaços de afinidade apresentam características referentes à sua configuração, aos seus tipos de interação e aos aprendizados por eles promovidos. No que tange à configuração de um espaço de afinidade, Gee aponta (utilizando como exemplo, um fansite ${ }^{8}$ de um jogo de estratégia em tempo real) que a organização estrutural é subserviente à organização interacional, ou seja, que são as interações que (re)(co)constroem o espaço, elegendo e alterando as ferramentas nele existentes e criando novas possibilidades; ele também aponta que os meios de acesso a espaços também servem como geradores de conteúdo para os espaços não se limitando a simples pontos de acesso.

Quanto aos tipos de interação, os espaços de afinidade não têm uma classificação em grupos como as comunidades de prática, mas estão agrupados com um interesse ou paixão em comum. Mesmo assim, há a possibilidade de destaque ou liderança por diversos membros, mas as figuras de liderança são vistas como recursos e fonte de informação, além de serem porosas e fluidas (configurando líderes como pares mais experientes no processo de aprendizado levando em consideração a interação na Zona de Desenvolvimento Proximal (VYGOTSKY, 1984) e a fluidez dos papéis de par mais e menos experiente). Acerca da promoção e valorização dos diversos tipos de aprendizado, os espaços de afinidade se caracterizam por valorizar diversas formas e maneiras de aprender, além de tipos de aprendizado (como o aprendizado coletivo, o extensivo e o expansivo, e não somente o individual, intensivo e restrito valorizado pelo sistema educacional) e oferece múltiplas rotas para aprendizes e obtenção de status (em detrimento do sistema de pontuação por índice em avaliações) (GEE, 2004).

Uma perspectiva sociocultural da promoção da autonomia que enfatize a utilização de ambientes com características dos espaços de afinidade, além de propiciar maiores oportunidades de interação que um ambiente tradicional poderia à primeira vista, também permite que o professor desenvolva seu olhar crítico. O professor, então, poderá observar os aspectos de ambientes utilizados que podem promover a autonomia em determinados grupos e de quais formas a participação dos interactantes (sem distinção entre alunos e professores) se constrói nos ambientes e que possivelmente podem também ser observadas em sala de aula. Através dessas observações, o professor (pesquisador) pode aprimorar seu olhar crítico sobre as ferramentas - especialmente, mas não de forma restrita, os ambientes - virtuais que lhe proporcionem resultados mais produtivos e melhor promovam a autonomia de seus alunos.

Como Blos e Nicolaides (2011) apontam em uma pesquisa sobre centros de autoacesso ${ }^{9}$, a promoção da autonomia do aprendiz

\footnotetext{
${ }^{8}$ Site criado, mantido e administrado por aficionados por um determinado conteúdo.

${ }^{9}$ Como centros de autoacesso as autoras se referem por espaços físicos que disponibilizam materiais para que os alunos acessem, conforme seus critérios de escolha, para promover a sua aprendizagem. Para mais aprofundamento sobre centro ver Gardner e Miller, 1999.
} 
[...] envolve além de questões individuais, [...] contexto, agência (OXFORD, 2003) e, principalmente, a ideia de interdependência (BENSON, 2001). Por último,[...] engloba a consciência do aprendiz no seu papel modificador do meio no qual está inserido (NICOLAIDES, 2003, p.16).

Mesmo que ainda sobre a perspectiva autocentrada dos centros observados, as autoras observam a importância da perspectiva sociocultural para a promoção da autonomia. Ao transpor os limites do individual, ao se estudar as motivações para o social presentes tanto em ambientes virtuais como em redes sociais, buscamos observar como ambientes virtuais podem despertar a consciência do aprendiz para seu papel e valor no aprendizado coletivo de sua turma.

A consciência desenvolvida poderá, então, implicar a maior participação em sala e na configuração de ambiente, facilitando a utilização por parte dos professores e transformando alunos em pares mais experientes (em relação aos professores, por exemplo), caso tenham maior afinidade com os ambientes utilizados. Cabe ao professor o papel de observar como as ferramentas digitais, em especial os ambientes virtuais - de afinidade - podem ser utilizadas pedagógica e criticamente no aprendizado de seus alunos. A partir destas reflexões, passamos agora a observar a utilização de dois ambientes virtuais como forma de aprimorar a discussão até aqui apresentada.

\section{Ambientes virtuais em uma sala de aula para a promoção de um processo de ensino e aprendizagem autônomo e socioculturalmente responsável}

Os dados aqui apresentados se originam de uma pesquisa em um contexto bastante específico. O ambiente físico, como o curso do qual ele faz parte, são frutos de uma parceria entre a Faculdade de Letras de uma Universidade Federal e de um Curso de Mestrado em Administração da mesma instituição. O objetivo do curso era o de capacitar seus funcionários para lidar com uma demanda de internacionalização ao instituir um curso para que estes possam ter aulas de língua inglesa para fins específicos, com uma metodologia focada para o contexto business, mas que também os prepare para lidar com o corpo discente cada vez mais diverso e multicultural, devido ao número crescente de indivíduos de outras nacionalidades no corpo discente.

Aqui faz-se necessário uma pausa para justificar a escolha peculiar deste contexto para observação e pesquisa. Dado o contexto até agora comentado, o educacional e, especificamente a sala de aula, é esperado que um projeto desta natureza não apresente as mesmas peculiaridades de um contexto escolar de ensino fundamental e médio. É compreensível o questionamento quanto à observação de um contexto deste tipo. No entanto, cabe aqui ressaltar que os ambientes observados com dado enfoque são os virtuais 
dos quais os alunos fizeram parte, sendo o contexto físico necessário para complementar a percepção holística da pesquisa, que busca seguir princípios da etnografia ou, nesse caso, a etnografia virtual ${ }^{10}$.

No contexto aqui observado, é necessário explicitar que seu público se constituía de muitos alunos que não utilizavam as tecnologias digitais para fins pedagógicos (muitos apresentavam até mesmo certa aversão ao meio digital). Além disso, como a implementação de ambientes virtuais no fazer pedagógico é relevante para educadores que ainda não iniciaram algum trabalho com tecnologias digitais em sua prática didática, o contexto observado nesta pesquisa parece ser adequado por apresentar percalços, como a falta de familiaridade com as tecnologias digitais, em seus momentos iniciais que resultam em considerações importantes nessa etapa do processo.

Para efeitos deste artigo, apresentamos dados originados de interactantes de uma única turma de nível inicial acompanhada a partir do segundo semestre de 2015, estando todos no segundo semestre de um projeto com níveis que levariam a um percurso com duração de três anos, com alunos de idades, experiência com tecnologias digitais e status empresarial bastante diferentes. Assim sendo, um enfoque maior no espaço e em suas possibilidades seria mais adequado para lidar com a heterogeneidade do grupo, apesar de também ser relevante a realização de pesquisas que levem em consideração como identidades tão diferentes se (re)(co)constroem enquanto atuam como alunos de uma mesma turma.

O ambiente projetado pelo pesquisador Matos, também professor da turma em questão, foi construído a partir do construtor de redes sociais (como assim se apresenta o website) http://yooco.org. O construtor possui diversas ferramentas e possibilita a criadores desenvolver e gerenciar (por meio de gráficos de controle, sistema de mensagens e análise de estatísticas, para nomear alguns) pequenos espaços de interação virtual de pequeno porte. Apesar de ser chamado por seus desenvolvedores de redes sociais, essa percepção pode ser alterada e o ambiente acaba sendo definido pelas interações nele contidas, como será observado posteriormente.

Inicialmente como repositório de exercícios, o ambiente foi pouco utilizado. Em reuniões com outros monitores que não foram transcritas (por serem em data anterior à pesquisa), mas das quais participamos, o maior problema relatado foi o de dificuldade no acesso e falta de costume com o ambiente. De fato, o ambiente havia sido criado há apenas algumas semanas antes das férias, a partir de uma sugestão feita para a coordenação pedagógica do projeto e pouco tempo foi dedicado a guiar aprendizes e monitores para melhor aproveitar seus recursos. Isso não só culminou em pouca utilização por parte dos alunos de todas as turmas durante as férias, mas também no abandono do ambiente por todas as outras turmas.

No início do primeiro semestre de 2015, o pesquisador Matos, também professor da turma a ser observada, optou por apresentar o ambiente aos alunos, bem como as possibilidades de atuação nele no início de duas das primeiras aulas. Além disso, os alunos foram informados do caráter opcional a respeito da utilização da plataforma, mas foram estimulados a participar pela prática na língua alvo e por ser uma

\footnotetext{
${ }^{10}$ Não cabe aqui uma discussão aprofundada sobre etnografia virtual ou netnografia. No entanto, Amaral et. al. (2008) apresentam um artigo dedicado aos termos.
} 
expansão do ambiente físico sala de aula, no qual os alunos também poderiam tirar dúvidas e ter um espaço de comunicação além dos muros do ambiente físico da sala de aula. É necessário reforçar que, dado o período inicial de implementação na turma específica, bem como a falta de experiência com contextos virtuais por parte dos alunos, foi necessário reforçar e explicar mais de uma vez os procedimentos para alunos diferentes, em momentos distintos. No entanto, as dúvidas posteriores foram em grande parte sanadas entre os próprios alunos, o que nos permitiu focar na interação com estes no ambiente virtual criado.

Além do ambiente virtual criado, outro ambiente foi proposto por um dos participantes, um grupo no aplicativo móvel Whatsapp. Em ambos os ambientes, a interação não tinha caráter exclusivamente pedagógico, mas como regra geral, criou-se um acordo entre alunos de não o utilizar na língua materna, salvo situações emergenciais (no caso do grupo do Whatsapp).

Os dados aqui apresentados se originam de transcrições de seis entrevistas e seis sessões de visionamento ${ }^{11}$ posteriores ao semestre, além das interações nos ambientes virtuais e anotações em diário de pesquisa durante o semestre letivo. Passamos agora a apresentar alguns dados sobre o ambiente virtual criado. Iniciamos sua apresentação trazendo uma figura de sua página inicial como vista pelos participantes.

Figura 1 - Página inicial do Ambiente Virtual

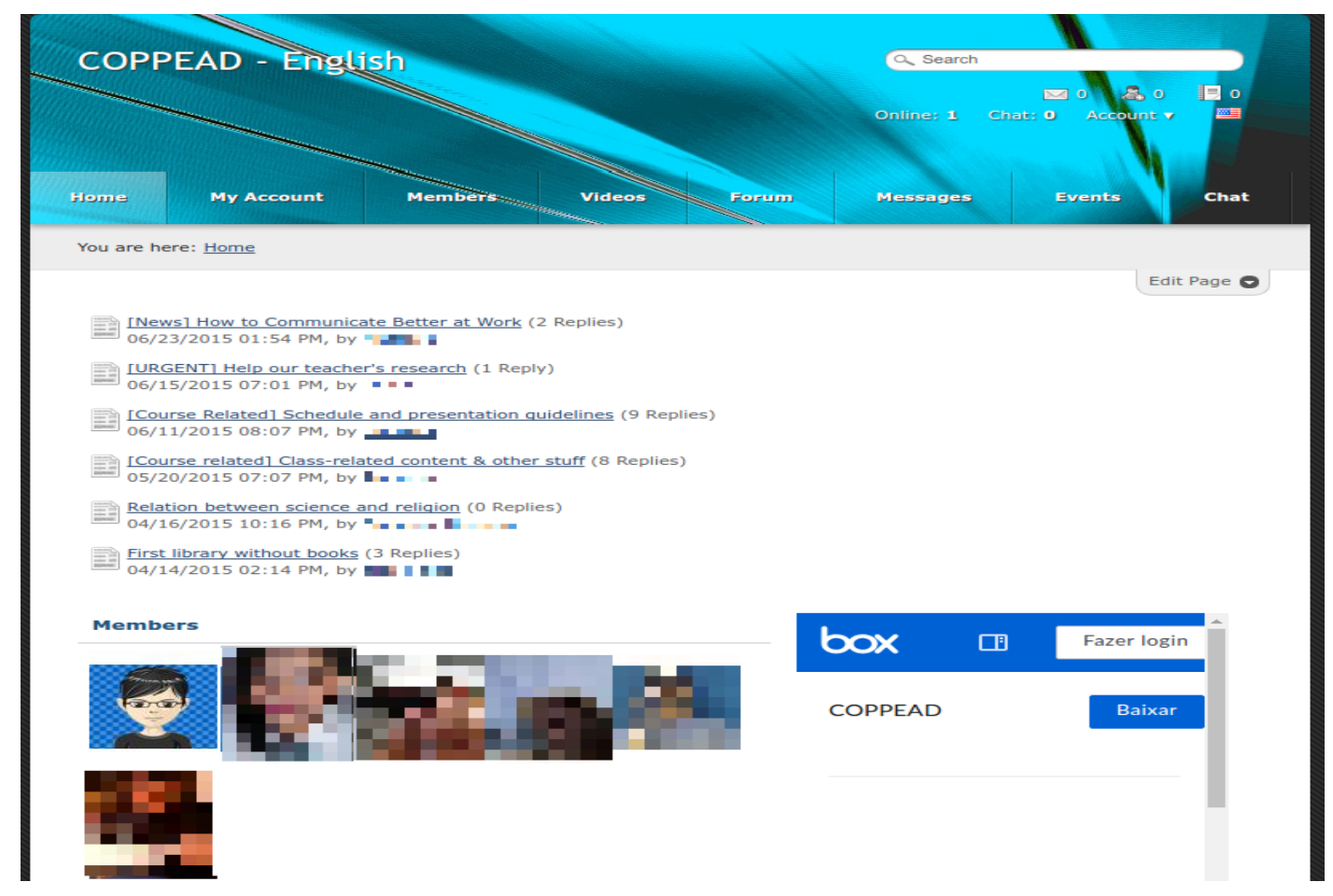

\footnotetext{
${ }^{11}$ Compreendemos sessões de visionamento, nesse contexto, como entrevistas tendo por base as interações dos participantes nos ambientes virtuais observados. Como nas sessões de visionamento tradicionais (nas quais os participantes observam suas ações em vídeo a fim de tecer considerações sobre tais ações), os participantes foram convidados a observar e comentar de forma detalhada sobre suas participações nos ambientes. Esses comentários foram gravados em áudio e vídeo e posteriormente transcritos para análise.
} 
Fonte: Gerada a partir do site http://yooco.org pelos autores (maiores detalhes foram omitidos para proteger a identidade dos participantes).

Sobre o primeiro ambiente virtual, muitos dos alunos participantes o enxergavam como fórum, dedicando grande parte da convivência no ambiente para postagem, leituras e comentários no fórum. Como é comum de espaços de afinidade, é o tipo de interação que define o espaço e, nesse caso, o ambiente se tornou um fórum, apesar de oferecer diversos outros recursos (como ferramentas de chat online por texto, áudio e vídeo, por exemplo). Quanto a este - ambiente virtual doravante chamado - fórum, os alunos apresentaram comentários geralmente positivos como o apresentado neste excerto:

Transcrição de entrevista no dia 30.06.2015

CARLA $^{12}$ : Quanto ao fórum eu acho até mais legal ainda porque significa que eu vi uma notícia em inglês, que eu entendi ela (mesmo que esse entendimento eu tenha eu tenho que ter procurado algumas palavras para poder compreender) $\mathrm{eu}$ achei legal e quis dividir. Então eu passei mais tempo ainda dedicando a isso, me dedicando a aprender o inglês e querer dividir com as outras pessoas gera discussão, e a discussão você tá utilizando a linguagem que você tá querendo aprender.

Neste excerto, CARLA apresenta a valorização da prática através do compartilhamento de notícias (uso comum do fórum) e do processo de aprendizado que a levou a postar, além de um retorno do que foi trabalhado ou visto para o debate, que também faz parte do aprendizado, mas sai da perspectiva individual e se preocupa em engajar seu grupo.

Ainda sobre o compartilhamento, agora não somente de notícias, trazemos comentários na sessão de visionamento de outra participante, LUÍSA, sobre suas postagens (a primeira compartilhando uma lista de exercícios sobre determinado tema apresentado em aula e outro sobre um conjunto de hiperlinks levando para artigos que abordassem o tema da escassez da água e preservação ambiental:

\section{Transcrição de sessão de visionamento no dia 24.06.2015}

LUÍSA: Quando você deu essa matéria, eu senti que a turma comentou, teve muitas dúvidas. Ai eu fui pesquisar, por acaso, encontrei esses exercícios e resolvi postar. Só que fui parando de fazer isso. [...] Eu não sabia como fazer, vou ser bem sincera, aí você explicou um dia em sala de aula como fazia para que as pessoas tivessem acesso a suas buscas, essas pesquisas a seus vídeos (vídeo nunca consegui postar, eu achava mas não conseguia) foi assim. Eu achei esse conteúdo bom, acrescentaria ao que você já tinha dado (uma lista de exercícios) e resolvi postar mas acho que foi só isso e o texto sobre o planeta, sobre a água.

Aí [sobre as postagens de artigos sobre preservação ambiental] eu pesquisei muito entrei muitos sites, e cada texto que eu lia, eu me apaixonava mais. [...] Eu tenho impressos, pois foram seis textos extremamente importantes, que motivaram muito a ler mais, pesquisar mais sobre esse tema. Até preparei uma apresentação sobre isso que eu nunca mostrei pra você, está lá, salva na minha pasta [...], acho que tem doze slides.

\footnotetext{
${ }^{12}$ Assim como todos os outros nomes, exceto ANDERSON (que se refere ao professor da turma e pesquisador responsável desta pesquisa), este é um nome fictício para preservar a identidade do sujeito envolvido na pesquisa.
} 
A partir deste excerto é possível notar que a aluna, apesar de expor sua inexperiência com postagens no fórum, pareceu se esforçar para participar e compartilhar suas informações como forma de contribuir para a aprendizagem do grupo. Ainda quanto sua contribuição, apesar de não ter tido a coragem suficiente para mostrar ao professor sua apresentação sobre o tema da discussão, LUISA demonstra fugir da passividade típica em uma perspectiva tradicional de papel de aluna e se torna mais empoderada no seu próprio processo de aprendizado, bem como a de seu grupo.

Quanto ao outro ambiente, vale notar que este foi criado e monitorado por alunos como forma alternativa de praticar e apontar possíveis imprevistos que impediram os integrantes de participar da aula.

Transcrição de entrevista em 30.06.2015

CARLA: Se você sair da sala de aula e começa a usar os espaços como o WhatsApp como o fórum que a gente tem, a gente tá estendendo esse aprendizado [...] posso ter escrito tudo errado, [mas] eu tô naquele momento fora aula torrando meu cérebro pra escrever da melhor forma possível.

Os tipos de participação no ambiente foram dos mais diversos possíveis, no entanto, é relevante apresentar alguns que contribuem para a discussão:

Interação no aplicativo Whatsapp em 27.02.2015

\begin{tabular}{|l|l|}
\hline 13:21, Feb 27 - LUÍSA: & Please repeat the exercises. \\
\hline 13:22, Feb 27 - CARLA: & Homework? \\
\hline 13:23, Feb 27 - LUÍSA: & Yes \\
\hline & $22: 48$, Feb 27 - CARLA removed $+5521 * * * * * * * * *$ \\
\hline & $22: 48$, Feb 27 - CARLA removed $+5521 * * * * * * * *$ \\
\hline $13: 34$, Feb 27 - CARLA: & $\begin{array}{l}\text { So, you choose some news and you write about it. With } \\
\text { this text you will try to convince our teacher that this } \\
\text { news is really good and important }\end{array}$ \\
\hline 13:35, Feb 27 - CARLA: & I understood this \\
\hline 13:46, Feb 27 - PEDRO: & OK. I understand. Only this? \\
\hline & $22: 48$, Feb 27 - CARLA added $+5521 * * * * * * * *$ \\
\hline $14: 37$, Feb 27 - LUÍSA: & Thank you CARLA \\
\hline
\end{tabular}

Interação no aplicativo Whatsapp em 30.04.2015

\begin{tabular}{|l|l|}
\hline 11:51, Apr 30 - CARLA: & $?$ \\
\hline 11:52, Apr 30 - PEDRO: & Which picture? All? \\
\hline 11:52, Apr 30 - CARLA: & The dates \\
\hline
\end{tabular}




\begin{tabular}{|l|l|}
\hline 11:53, Apr 30 - CARLA: & I cannot see the dates \\
\hline 11:54, Apr 30 - CARLA: & But, that's OK. Next class I will ask to Anderson. \\
\hline 11:54, Apr 30 - CARLA: & Thanks, baby \\
\hline 12:15, Apr 30 - PEDRO: & $\begin{array}{l}\text { OK. But 18/06 and 23/06 will presentation about our job } \\
\text { for } 15 \text { min. We will talk about other subject, in relation } \\
\text { the first presentation. It's alrigth? }\end{array}$ \\
\hline 12:15, Apr 30 - PEDRO: & Oh my god. Kkkkk \\
\hline
\end{tabular}

Com base nas interações no aplicativo, é possível perceber que alunos se empenham em sanar dúvidas de seus colegas e interagir na língua alvo. Uma maior preocupação com o aprendizado do grupo pôde ser observada em sala, as quais trazemos sob a forma de anotações no diário de pesquisa:

Diário do professor do dia 16.06.2015

Acabei fazendo uma review gramatical com os alunos, e é esse o ponto que achei interessante. Os alunos quiseram tirar fotos do quadro para compartilhar com o grupo no whatsapp mesmo tendo copiado manualmente no caderno. Quando perguntei sobre isso, por pura curiosidade, a ALINE comentou que era para a CARLA, uma aluna que havia faltado no dia.

Além disso, usei do tempo do curso para agendar as entrevistas e, para minha surpresa, eles também se organizaram de modo a pensar em um melhor horário não só para eles, mas para os alunos que haviam faltado ${ }^{13}$.

Ainda sobre compartilhamento, é possível perceber pelos excertos apresentados uma preocupação com o grupo social no qual o aprendizado está situado por parte dos alunos. Ainda que a tecnologia tenha proporcionado maior autonomia no sentido clássico (ou seja, sob uma perspectiva individual), eles acabaram por se responsabilizar pelo aprendizado do grupo como um todo. Como os dois últimos excertos mostrarão, até mesmo alunos sem muita experiência com tecnologias digitais, podem se apropriar de características do ambiente.

\section{Transcrição de entrevista em 24.06.2015}

LUÍSA: Desde o início, tive muita dificuldade, ainda tenho, até pra acessar. Todas as vezes eu vou procurar nos meus cadernos, anotações, e eu [acho que] anotei alguma coisa errada. [...] Se não tiver o caderno em casa eu entro em pânico, eu vou procurar mensagens antigas no celular porque eu não lembro. Mas é um ambiente que poderia, poderia nos ajudar, e muito, porque os fóruns que que a gente tem ali abrem um leque de possibilidades mil pra facilitar, é aprendizagem fora da sala de aula[... $]^{14}$

Apesar de se mostrar com dificuldades, LUÍSA se mostra favorável quanto ao uso do fórum, ainda que tenha participado com contribuições temáticas e até pedagógicas dentro do ambiente, uma de suas contribuições em sala apresenta características dos ambientes virtuais e foi notada em diário de pesquisa:

Diário do professor do dia 11.06.2015

\footnotetext{
${ }^{13}$ Marcações em itálico presente no diário de pesquisa original.

${ }^{14}$ Marcação em itálico apenas como identificador de destaque posterior à transcrição. A marcação não indica desvio ou diferenciação na entonação da fala do participante.
} 
[...] achei também interessante a LUÍSA ter trago um artigo sobre erros que aprendizes de inglês cometem pra, nas palavras dela, "compartilhar com a turma". Mesmo ela não se dando muito bem com o conhecimento tecnológico, ela pegou a ideia do espaço virtual e aplicou no meio físico.

Com tal atitude, LUÍSA mostrou-se não se restringir ao ambiente virtual, mas como usuária das características dos ambientes virtuais para promover a autonomia sociocultural de seu grupo. Ao optar pelo uso do termo "compartilhar", ela possivelmente mostra uma relação com a prática proporcionada pelos ambientes virtuais os incorporando a sua prática no espaço físico.

\section{Considerações finais}

Com base nos dados e na discussão anteriormente apresentados, foi possível perceber que a implementação de ambientes virtuais pode proporcionar experiências de aprendizado que tornem alunos mais engajados e pró-ativos em seu processo de aprendizado. Em outras palavras, ao utilizar ambientes virtuais para a promoção da autonomia sociocultural, pode-se fazer com que alunos experienciem novos papéis enquanto interactantes, não somente alunos e, a partir destas experiências, permitir que se tornem mais responsáveis pelo seu próprio aprendizado e pelo aprendizado de seu grupo.

Ao observar o ambiente como campo de possibilidades, deve-se atentar para a relevância das ferramentas nele apresentadas e como a interação pode redefinir quais seriam as mais adequadas. Acreditamos ser pouco produtivo restringir ou modificar o uso de ferramentas dentro de ambientes virtuais nos quais os interactantes já "elegeram" suas favoritas (seria pouco produtivo forçar interações de chat, por exemplo, em detrimento do fórum no ambiente virtual ou não valorizar o favoritismo deste pelos seus usuários; ou ainda deixar de legitimar a participação e interação no aplicativo Whatsapp por não ter sido iniciativa do professor).

Com base nas configurações de um espaço de afinidade, muitos dos problemas quanto aos papéis de professores e alunos, especialmente sobre a inserção e trabalho com ferramentas digitais, são passíveis de reflexão. É possível que alunos tomem o papel de liderança ao compartilhar temas, apresentar tarefas complementares e até mesmo avaliar e eleger ferramentas e ambiente por si mesmos; cabe ao professor orientar quanto ao olhar crítico e potencial pedagógico das ferramentas digitais, em especial, dos ambientes virtuais que possam se configurar como espaços de afinidade. Além disso, utilizar ferramentas digitais como campos para a promoção da autonomia sociocultural pode engajar os alunos para um aprendizado consciente e os responsabilizar para maximizar as possibilidades de aprendizado de todos. Até mesmo alunos que se sintam pouco adeptos à experiência podem se beneficiar do comportamento visto nos ambientes virtuais e encontrar formas de utilizá-lo no meio físico.

Muito ainda depende de instituições e de secretarias de educação que acabam não estimulando o aprimoramento de professores, ou mesmo dado espaço para que reflitam sobre a melhor forma de otimizar 
de forma crítica a utilização de tecnologias, mas entender a autonomia como socialmente construída e engajada, poderia auxiliar professores que já estão motivados a um caminho de aprendizado com seus alunos.

O uso de ferramentas digitais, e sobretudo dos ambientes virtuais, pode se tornar uma opção metodológica enriquecedora e que envolva os alunos (e o professor) no processo de aprendizado, na responsabilidade com o grupo e criticidade quanto ao material e temas abordados e, sobretudo, a superação pessoal e aquisição de atitudes e comportamentos que vencem a barreira do pouco conhecimento tecnológico para um melhor aprendizado real e, por que não, virtual.

\section{Referências Bibliográficas}

AMARAL, A.; NATAL, G.; VIANA, L. Netnografia como aporte metodológico da pesquisa em comunicação digital. Cadernos da Escola de Comunicação, v.6, n.1, p. 34-40, 2008. Disponível em: http://revistaseletronicas.pucrs.br/ojs/index.php/famecos/article/viewFile/4829/3687, acesso em 24 outubro 2018.

BAUMAN, Z.; LYON, D. Liquid Surveillance: A Conversation. Cambridge: Polity, 2012.

BENSON, P. Teaching and researching autonomy in language learning. Harlow/New York, Pearson Education Limited, 2001.

BLOS, D.; NICOLAIDES, C. A aprendizagem autônoma de crianças aprendizes de línguas em um contexto de ensino de currículo bilíngue por meio de um centro de autoacesso (Calidoscópio, Vol. 9, p. 15-27, jan/abr 2011) Unisinos -doi. Disponível em:

http://www.unisinos.br/revistas/index.php/calidoscopio/article/download/680/150, acesso em 22 outubro 2018.

BUZATO, M. E. K. 2006. Letramentos Digitais e Formação de Professores. Anais do III Congresso IberoAmericano Educarede. São Paulo: CENPEC. 81-86.

DANG, T. T. Learner Autonomy in EFL Studies in Vietnam: A Discussion from Sociocultural Perspective English Language Teaching, Vol. 3, No. 2 (pp. 3-9). 2010.

GARDNER, D.; MILLER, L. Establishing Self-Access: from Theory to Practice. Cambridge: Cambridge University Press, 1999.

GEE, J. P. Situated Language and Learning: A Critique of Traditional Schooling. New York: Routledge, 2004

GEE. J. P. Semiotic social spaces and affinity spaces: from The Age of Mythology to today's schools in BARTON, D. \& TUSTING, K. (Eds.), Beyond communities of practice: Language, power and social context (pp. 214-232). Cambridge: Cambridge University Press, 2005.

HOLEC, H. Autonomy in foreign language learning. Oxford: Pergamon, 1981.

HUNTER, J.; COOKE, D. Through autonomy to agency: Giving power to language learners. IN: Prospect Vol. 22, No. 2, 2007.

LANKSHEAR, C.; KNOBEL, M. Introduction: digital literacies: concepts, policies and practices. In: LANKSHEAR, C.; KNOBEL, M. (eds.) Digital literacies: concepts, policies and practices. Peter Lang Publishing, New York, USA, pp. 1-16. 2008.

KNOBEL, M.; LANKSHEAR, C. (eds) (2010) DIY Media: Creating, Sharing and Learning with New Technologies. New York: Peter Lang Publishing. 2010.

LAVE, J.; WENGER, E. Situated learning: legitimate peripheral participation. Cambridge: Cambridge University Press, 1991.

MATOS, A. S. Os ambientes virtuais como campos para a promoção da autonomia sociocultural em ensinagem de língua adicional. Dissertação (Mestrado Interdisciplinar em Linguística Aplicada) Universidade Federal do Rio de Janeiro, Rio de Janeiro, 2017.

MILLS, K. A. A review of the digital turn in the New Literacy Studies. Review of Educational Research, Vol.80. No. 2, p.246-271. 2010. 
OXFORD, R.L. 2003. Toward a more systematic model of L2 learner autonomy. In PALFREYMAN, D.; SMITH, R.C. Learner Autonomy Across Cultures: Language Education Perspectives. London, Palgrave Macmillan Ltd., p. 75-91. 2003.

PERKEL, D. Letramento do copiar e colar? práticas de letramento na produção de um perfil MySpace. Trab em Linguística Aplicada., vol.49, n.2, pp. 493-511. 2010. Disponível em:

http://www.scielo.br/scielo.php?script=sci arttext\&pid=S0103-18132010000200011, acesso em 23 outubro 2018.

ROJO, R. Pedagogia dos multiletramentos: diversidade cultural e de linguagens na escola. In: ROJO, R.; MOURA, E. (Orgs.). Multiletramentos na escola. São Paulo: Parábola Editorial, p. 11-31. 2012.

TAVARES, K. A formação do professor on-line: de listas de recomendações à reflexão crítica. Palestra ministrada no II Seminário de Estudos em Linguagem, Educação e Tecnologia, Faculdade de Letras, UFRJ, de 21 a 31 de maio de 2007.

VYGOTSKY, L.S. A Formação Social da Mente. São Paulo, Martins Fontes, 1984.

WENGER, E. et al. Cultivating Communities of Practice. Harvard Business School Press: Boston, 2002.

Anderson Silva MATOS has a Master's Degree from the Interdisciplinary Post-Graduation Program in Applied Linguistics at UFRJ. Doctoral student from the Interdisciplinary Post-Graduation Program in Applied Linguistics at UFRJ. Substitute Professor of English for Academic Purposes in Faculty of Letters /UFRJ.Email: matos.andersonsilv@gmail.com

Christine NICOLAIDES is a Ph.D. in Letters from UFRGS. Associate Professor of English at UFRJ and researcher at the Interdisciplinary Post-Graduation Program in Applied Linguistics. Former President of the Brazilian Association of Applied Linguistics (2011-2013) and visiting scholar at SFSU, U.S.A. (2017).Email: christine.nicolaides@gmail.com 